\title{
REVIEW
}

\section{Hyperemesis gravidarum: current concepts and management}

N K Kuşcu, F Koyuncu

Postgrad Med J 2002;78:76-79

Hyperemesis gravidarum is a common problem for an obstetrician. Though nausea and vomiting are quite common in pregnancy, hyperemesis is found in only 1-20 patients per 1000. In this practical review, a general outline of the syndrome, its relation to the gastrointestinal system and thyroid, mild and rare severe complications, and conventional treatment versus newer options are discussed.

$\mathrm{H}$ yperemesis gravidarum is defined as vomiting in pregnancy that is sufficiently pernicious to produce weight loss, dehydration, acidosis from starvation, alkalosis from loss of hydrochloric acid in vomitus, and hypokalaemia. ${ }^{1}$ All these symptoms are not absolutely necessary for the diagnosis. Mild to moderate ketonuria may be seen in urinary analysis. High or rapidly rising steroids seem to play a part in aetiology, and raised liver enzymes are seen in $15 \%-25 \%$ of women who are hospitalised. ${ }^{2}$ Enzyme levels are not usually increased more than four times the upper normal limit. Risk factors vary among different populations and female sex of the offspring, several previous pregnancies, and a high daily intake of primarily saturated fat before pregnancy are reported to cause a higher risk..$^{3-5}$ Besides these factors, gestational trophoblastic disease, multiple pregnancy, and psychology of the patient are other major concerns. Serum amylase levels have been reported to rise in some of the patients with hyperemesis gravidarum, and this amylase comes from the salivary gland not from the pancreas. ${ }^{6}$ Immunological factors such as immune globulins, C3, C4, and lymphocyte counts were found to be significantly higher in hyperemesis gravidarum, which may suggest a role for immunological activity in pregnancy. ${ }^{7}$ If thyrotoxicosis accompanies hyperemesis, mean serum $\beta$-human chorionic gonadotrophin (hCG), $\operatorname{Ig} G$, and $\operatorname{IgM}$ concentrations rise to a higher extent. These factors may exaggerate the stimulatory effect of $\beta$-hCG. In addition, a positive relationship between hyperemesis and maternal serum prostaglandin E2 concentrations was detected. ${ }^{8}$

Gastric emptying and intestinal transit times may be delayed in pregnancy because of hormonal or mechanical factors. But, on the contrary, gastric emptying of solids was reported not to change during pregnancy'; however, in patients recovering from hyperemesis gravidarum, solid emptying time was found to increase, correlating with abnormal thyroid hormones. ${ }^{10}$
Submitted 13 June 2001

Accepted

19 October 200

....................
The role of serotonin (5-hydoxytryptamine) was investigated, but no association between increased serotonin secretion and hyperemesis gravidarum was found. ${ }^{11}$ However, several serotonin receptor subtypes have been shown to be related to emesis. ${ }^{12}$

Helicobacter pylori infection is reported to be associated with hyperemesis gravidarum..$^{13}$ Serum IgG concentrations raised against $H$ pylori are higher in patients with hyperemesis gravidarum when compared with asymptomatic pregnant women. Two patients with severe hyperemesis gravidarum responded dramatically to oral erythromycin therapy, which they were taking for other non-related conditions, and who were later found to be seropositive for $H$ pylori. ${ }^{15}$ Three other patients refractory to standard medical therapy were given antibiotics and a proton pump inhibitor or $\mathrm{H}_{2}$ receptor antagonist and hyperemesis resolved. ${ }^{2}$ Persistent nausea and vomiting beyond the second trimester should raise suspicions of an active peptic ulcer caused by $H$ pylori.

\section{HYPEREMESIS GRAVIDARUM AND THE THYROID}

Thyroid function changes with the onset of pregnancy: thyroxine binding globulin, total triiodothyronine and thyroxine concentrations, thyroglobulin, and renal iodide clearance all increase. Also hCG has mild thyroid stimulating activity. ${ }^{17}$ Transient hyperthyroidism is seen in about $60 \%$ of patients with hyperemesis gravidarum. ${ }^{18} 19$ The increase in thyroid hormones is attributable to either higher hCG concentrations, or hCG hypersensitive thyrotrophin receptors in an overactive thyroid, ${ }^{20}$ or probable secretion of a variant of hCG with increased thyroid stimulating activity. ${ }^{21}$ Patients with transient hyperthyroidism have no previous thyroid illness, goitre is usually absent, and thyroid antibodies are negative. These patients are more likely to have abnormal liver function tests and electrolytes. The more severe the vomiting the greater degree of thyroid stimulation and the higher the concentration of hCG. ${ }^{22}$ Transient hyperthyroidism may be responsible for $40 \%-70 \%$ of thyroid function abnormalities in pregnancy and usually resolves by 18 weeks without treatment and sequelae. ${ }^{23}$ Only a small proportion of these patients have clinical thyrotoxicosis and maybe these are the patients who secrete a more potent molecular variant of hCG. ${ }^{21}$ Besides hyperemesis gravidarum occurring during the first pregnancy, recurrence in two

Abbreviations: $h C G$, human chorionic gonadotrophin 
consecutive pregnancies has been reported. ${ }^{24}$ Hyperemesis gravidarum was seen in three consecutive pregnancies and transient hyperthyroidism was diagnosed in two of them. A modified variant of hCG was considered to play a part in this recurrence.

\section{COMPLICATIONS OF HYPEREMESIS GRAVIDARUM}

Both relatively benign and pernicious complications may be caused by hyperemesis gravidarum. Weight loss, dehydration, acidosis from malnutrition, alkalosis from vomiting, hypokalaemia, muscle weakness, electrocardiographic abnormalities, tetany, and psychological disturbances may be included in the "benign" group. Life threatening complications include oesophageal rupture due to severe vomiting, Wernicke's encephalopathy, central pontine myelinolysis, retinal haemorrhage, renal damage, spontaneous pneumomediastinum, intrauterine growth retardation, and fetal death. ${ }^{25-33}$ A patient with hyperemesis gravidarum has been reported to have had epistaxis at the 15th week of gestation because of an inadequate intake of vitamin $\mathrm{K}$ caused by severe emesis and her inability to tolerate solids and fluids. ${ }^{34}$ With replacement of vitamin K, coagulation parameters returned to normal and the disorder resolved. Vasospasm of cerebral arteries associated with hyperemesis gravidarum was reported in two patients. ${ }^{35}$ The vasospasm was diagnosed by magnetic resonance imaging angiography and the patients responded to fluid and electrolyte replacement.

\section{MANAGEMENT OF HYPEREMESIS GRAVIDARUM}

Appropriate parenteral fluid and electrolyte replacement is the initial treatment regimen for hyperemesis gravidarum. Various antiemetics may be given with vitamin supplementation. Promethazine, prochlorperazine, chlorpromazine, meclizine, droperidol-diphenhydramine, and metoclopramide are commonly used agents to alleviate nausea and vomiting. The intravenous or rectal route can be used initially and changed to the oral route when the symptoms begin to subside. If no response is observed within several days and the symptoms persist to an even higher degree, gastroenteritis, cholecystitis, pancreatitis, hepatitis, peptic ulcer, pyelonephritis, and the fatty liver of pregnancy must be included in the differential diagnosis and the patient must be evaluated in this order. Psychological support from both the medical team and the patient's family is an additive to the management. The patient must avoid foul smells and undesired foods as both may trigger vomiting. After discharge from hospital the syndrome recurs in some patients and rehospitalisation may be necessary. ${ }^{36}$ Besides antiemetic medications, pyridoxine appears to be more effective in reducing the severity of nausea. ${ }^{37}$ Adrenocorticotrophic hormone had no benefit, ${ }^{38}$ but ginger was found to diminish or eliminate the symptoms of hyperemesis gravidarum without any side effects. ${ }^{39}$ The mutagenic effects of ginger are not known in humans.

The relative risk for major malformations in the offspring of patients who were exposed to antihistamines in the first trimester was determined by evaluating 24 controlled studies involving more than 200000 women. $^{40}$ The odds ratio for major malformations was found to be 0.76 (98\% confidence interval 0.60 to 0.94 ). No increase in teratogenic risk was determined, and antihistamines were found to be safe if prescribed during pregnancy.

In an evaluation of 50 patients with hyperemesis gravidarum, the addition of diazepam to fluid and vitamin therapy was reported to be effective in reducing nausea. ${ }^{41}$ No teratogenic effects of diazepam were seen. But it must be kept in mind that diazepam is a class D drug according to the Food and Drug Administration categories and should be used with caution and probably be avoided as an initial treatment even in refractory cases.

\section{Newer drugs}

Continuous droperidol infusion and bolus intravenous diphenhydramine were studied in hyperemesis gravidarum and compared with other patients who did not receive any of the drugs. ${ }^{42}$ The study group had a shorter stay in hospital with fewer readmissions. Droperidol-diphenhydramine treatment was reported to be both beneficial and cost effective.

Ondansetron is a 5-hydroxytryptamine receptor antagonist which is used to prevent severe nausea and vomiting during chemotherapy and in the postoperative period. It is listed as a category B drug but is usually avoided during the first trimester. Though serotonin is not implicated in the pathogenesis of hyperemesis gravidarum, ${ }^{11}$ ondansetron may be reserved for refractory cases. No adverse effect for either the mother or the fetus was seen in one patient who was treated with the drug intermittently in every trimester. ${ }^{43}$ On the contrary, no benefit over promethazine has been reported when the two drugs were compared in a double blinded fashion including 15 patients in each group. ${ }^{44}$ No difference in the relief of nausea, weight gain, and days of hospitalisation was seen.

Steroids may be used as an alternative regimen in patients refractory to standard therapy. It was first reported in 1953 that cortisone treatment led to complete cessation of hyperemesis. ${ }^{45}$ Since then, various forms of therapy have been used. A short course of methylprednisolone, $16 \mathrm{mg}$ three times daily, tapering the dose during the course of two weeks was found to be more effective when compared with promethazine. ${ }^{46}$ There was a significant difference rate in readmission of patients. Birth weight and Apgar scores did not differ. The drug is thought to exert its effect through the chemoreceptor trigger zone located in the brain stem. This mode of therapy could be begun in the hospital and continued in an outpatient setting and reserved for patients refractory to standard intravenous hydration and antiemetics. In another study intravenous hydrocortisone was followed with oral prednisolone in seven patients with intractable hyperemesis gravidarum. ${ }^{47}$ Vomiting stopped within three hours of the first dose of hydrocortisone and the symptoms resolved within days with the resumption of normal eating, reversal of muscle wasting, and regain of lost weight.

Parenteral nutrition may be necessary in severe cases. ${ }^{48}$ Enteral feeding is an alternative approach after acute symptoms subside with initial therapy. ${ }^{49}{ }^{50}$ This form of nutrition should be considered in patients who cannot tolerate oral feeding despite antiemetic treatment. Sometimes it is quite difficult for a patient to eat with the burden of severe nausea and vomiting. Hsu et al used a nasogastric feeding tube in seven women with intractable vomiting for nutritional supplementation; this was found to be effective in relieving the symptoms of hyperemesis gravidarum.

Maternal and fetal outcomes of hyperemesis gravidarum were investigated in two different studies involving 193 and 138 patients respectively. ${ }^{51} 52$ Of 193 patients, 24\% required hospitalisation and one patient required parenteral nutrition. Birth weight, gestational age, preterm delivery, Apgar scores, perinatal mortality, and incidence of fetal anomalies did not differ between hyperemetic patients and the general population. In the other study, no increased risk of growth retardation, congenital anomalies, and prematurity was detected.

In conclusion, vomiting and/or nausea are common during pregnancy but hyperemesis gravidarum occurs in 1-20 patients per $1000 .^{30}$ Most patients require hospitalisation and antiemetics and even short term steroid therapy. Serious complications are rare but medical therapy is mandatory. Hyperthyroidism may be found in about $60 \%$ of patients, but may not require specific therapy. $H$ pylori infection must be considered in intractable cases and appropriate antibiotics should be given. Enteral feeding is an alternative therapy for refractory cases. 


\section{Key references}

- Leylek OA, Tayaksi M, Ercelsan T, et al. Immunologic and biochemical factors in hyperemesis gravidarum with or without hyperthyroxinemia. Gynecol Obstet Invest 1999;47:229-34

- Fantz CR, Dagogo JS, Ladenson JH, et al. Thyroid function during pregnancy. Clin Chem 1999;45:2250-8

- Seto A, Einarson T, Koren G. Pregnancy outcome following first trimester exposure to antihistamines: meta-analysis. Am J Perinatol 1997;14:1 19-24.

- Safari HR, Fassett M, Souter IC, et al. The efficacy of methylprednisolone in the treatment of hyperemesis gravidarum: a randomized, double-blind, controlled study. Am J Obstet Gynecol 1998;179:921-4

- Tsang IS, Katz VL, Wells SD. Maternal and fetal outcomes in hyperemesis gravidarum. Int J Gynaecol Obstet 1996;55:231-5

\section{QUESTIONS (ANSWERS ON NEXT PAGE)}

1. What is the incidence of hyperemesis gravidarum (per 1000 pregnant patients)?
(A) 10
(B) 25
(C) 35
(D) 50
(E) 100

\section{Which one of the following statements about} hyperemesis gravidarum is false?

(A) Acidosis occurs due to negative energy balance.

(B) Ketonuria is not the sine qua non of the syndrome.

(C) Nausea is accepted to be the result of high steroid levels.

(D) Raised liver enzymes may be seen in severe cases.

(E) Perinatal morbidity and mortality rates are high in hyperemetic patients.

\section{What is the mechanism of hyperthyroidism seen in} patients with hyperemesis gravidarum?

(A) hCG may stimulate the thyroid.

(B) Thyrotrophin receptors may be more sensitive to hCG.

(C) Both.

(D) None.

\section{Which treatment is used for hyperthyroidism seen in} patients with hyperemesis gravidarum?

(A) Propylthiouracil.

(B) Methimazole.

(C) Propranolol.

(D) Surgery.

(E) None.

\section{Which one of the following statements is false about treatment of the syndrome?}

(A) Antihistamines are usually the initial step for management of the syndrome, and they are safe to use during the first trimester.

(B) Short term steroid therapy may be given to intractable cases.

(C) Ondansetron may be superior to antihistamines.

(D) Total parenteral nutrition should be given in severe form.

(E) Psychological support is very important and should be given by both the family of the patient and the medical team.
Authors' affiliations

N K Kuşcu, F Koyuncu, Celal Bayar University, School of Medicine,

Department of Obstetrics and Gynaecology, Manisa, Turkey

\section{REFERENCES}

1 Cunningham FG, MacDonald PC, Gant NF, et al. Williams obstetrics. Connecticut: Appleton \& Lange, 1997: 1146.

2 Morali GA, Braverman DZ. Abnormal liver enzymes and ketonuria in hyperemesis gravidarum. A retrospective view of 80 patients. J Clin Gastroenterol 1990;12:303-5.

3 Signorello LB, Harlow BL, Wang S, et al. Saturated fat intake and the risk of severe hyperemesis gravidarum. Epidemiology 1998;9:636-40.

4 Askling J, Erlandsson G, Kaijser $M$, et al. Sickness in pregnancy and sex of child. Lancet 1999:354:2053.

5 Vilming B, Nesheim BI. Hyperemesis gravidarum in a contemporary population in Oslo. Acta Obstet Gynecol Scand 2000;79:640-3.

6 Robertson C, Millar H. Hyperamylasemia in bulimia nervosa and hyperemesis gravidarum. Int J Eat Disord 1999;26:223-7.

7 Leylek OA, Tayaksi M, Ercelsan T, et al. Immunologic and biochemical factors in hyperemesis gravidarum with or without hyperthyroxinemia. Gynecol Obstet Invest 1999;47:229-34.

8 Gadsby R, Barnie-Adshead A, Grammatoppoulos D, et al. Nausea and vomiting in pregnancy: an association between symptoms and maternal prostaglandin E2. Gynecol Obstet Invest 2000;50:149-52.

9 Macfie AG, Magides AP, Richmond MH, et al. Gastric emptying in pregnancy. BrJ Anaesth 1991;67:54

10 Maes BD, Spitz B, Ghoos YF, et al. Gastric emptying in hyperemesis gravidarum and non-dyspeptic pregnancy. Aliment Pharmacol Ther 1999:13:237-43

11 Borgeat A, Fathi M, Valiton A. Hyperemesis gravidarum: is serotonin implicated? Am J Obstet Gynecol 1997; 176:476-7

12 Hasler WL. Serotonin receptor physiology: relation to emesis. Dig Dis Sci 1999:44(8 suppl): 108S-13S.

13 Frigo $\mathbf{P}$, Lang $\mathrm{C}$, Reisenberger K, et al. Hyperemesis gravidarum associated with Helicobacter pylori seropositivity. Obstet Gynecol 1998;91:615-7.

14 Kocak I, Akcan Y, Ustun C, et al. Helicobacter seropositivity in patients with hyperemesis gravidarum. Int J Gynaecol Obstet 1999;66:251-4.

15 El Younis CM, Abulafia O, Sherer DM. Rapid marked response of severe hyperemesis gravidarum to oral erythromycin. Am J Perinatol 1998; 15:533-4.

16 Jacoby EB, Porter KB. Helicobacter pylori infection and persistent hyperemesis gravidarum. Am J Perinatol 1999:16:85-8.

17 Fantz CR, Dagogo JS, Ladenson JH, et al. Thyroid function during pregnancy. Clin Chem 1999;45:2250-8

18 Goodwin TM, Montero M, Mestman JH. Transient hyperthyroidism and hyperemesis gravidarum: clinical aspects. Am J Obstet Gynecol 1992; 167:648-52.

19 Leylek OA, Cetin A, Toyaksi M, et al. Hyperthyroidism in hyperemesis gravidarum. Int J Gynaecol Obstet 1996;55:33-7.

20 Rodien P, Bremont C, Sanson M-LR, et al. Familial gestationa hyperthyroidism caused by a mutant thyrotopin receptor hypersensitive to human chorionic gonadotropin. N Engl J Med 1998;339: 1823-6.

21 Hershman JM. Human chorionic gonadotropin and the thyroid: hyperemesis gravidarum and trophoblastic tumors. Thyroid 1999;9:653-7.

22 Goodwin TM, Montero M, Mestman JH, et al. The role of chorionic gonadotropin in transient hyperthyroidism of hyperemesis gravidarum. $J$ Clin Endocrinol Metab 1992;75:1333-7.

23 Caffrey TJ. Transient hyperthyroidism of hyperemesis gravidarum: a sheep in wolf's clothing. J Am Board Fam Pract 2000; 13:35-8.

24 Nader S, Mastrobattistita J. Recurrent hyperthyroidism in consecutive pregnancies characterized by hyperemesis. Thyroid 1996:6:465-6.

25 Henry R, Vadas R. Spontaneous rupture of the oesophageus following severe vomiting in early pregnancy: a case report. Br J Obstet Gynaecol 1986;93:392-4

26 Woolford TJ, Birzgalis AR, Lundell C, et al. Vomiting in pregnancy resulting in esophageal perforation. J Laryngol Otol 1993;107:105960.

27 Wood P, Murray A, Sinha B, et al. Wernicke's encephalopathy induced by hyperemesis gravidarum: case reports. Br J Obstet Gynaecol 1983;90:583-6.

28 Rees JH, Ginsberg L, Schapira AHV. Two pregnant women with vomiting and fits. Am J Obstet Gynecol 1997; 177:1539-40.

29 Bergin PS, Harvey P. Wernicke's encephalopathy and central pontine myelinolysis with hyperemesis gravidarum. BM 1992;305:517-8.

30 Fairweather DVI, Loraine JA. Nausea and vomiting in pregnancy. Am J Obstet Gynecol 1968;102:135-73.

31 Gorbach JJ, Counselman FL, Mendelson MH. Spontaneous pneumomediastinum secondary to hyperemesis gravidarum. J Emerg Med 1997; 15:639-43

32 Chin RKH, Lao TT. Low birth weight and hyperemesis gravidarum. Eur $J$ Obstet Gynecol 1988;28:179-83.

33 Stellato TA, Danziegr LH, Pharm D, et al. Fetal salvage with maternal TPN:the pregnant mother as her own control. J Parenteral Enteral Nutr 1988; 12:412-3

34 Robinson JN, Anerjee R, Thiet MP. Coagulopathy secondary to vitamin $\mathrm{K}$ deficiency in hyperemesis gravidarum. Obstet Gynecol 1998;92:673-5. 
35 Kanayama N, Khatun S, Belayet HM, et al. Vasospasms of cerebral arteries in hyperemesis gravidarum. Gynecol Obstet Invest 1998;46:139-41.

36 Godsey RK, Newman RB. Hyperemesis gravidarum: a comparison of single and multiple admissions. J Reprod Med 1991;36:287-90.

37 Jewell D, Young G. Interventions for nausea and vomiting in early pregnency. Cochrane Database Syst Rev 2000;2:CD000145.

38 Yliorkala D, Kauppila A, Ollanketo ML. Intramuscular ACTH or placebo in the treatment of hyperemesis gravidarum. Acta Obstet Gynecol Scand 1979;58:453-5.

39 Fischer-Rasmussen W, Kjaer SK, Dahl C, et al. Ginger treatment of hyperemesis gravidarum. Eur Obstet Gynecol Reprod Biol 1991;38:19-24.

40 Seto A, Einarson T, Koren G. Pregnancy outcome following first trimester exposure to antihistamines: meta-analysis. Am J Perinatol 1997; 14:119-24.

41 Ditto A, Morgante G, la Marca A, et al. Evaluation of treatment of hyperemesis gravidarum using parenteral fluid with or without diazepam. A randomized study. Gynecol Obstet Invest 1999;48:232-6

42 Nageotte MP, Briggs GG, Towers CV, et al. Droperidol and diphenhydramine in the management of hyperemesis gravidarum. Am J Obstet Gynecol 1996;174:1801-5.

43 Tincello DG, Johnstone M. Treatment of hyperemesis gravidarum with the 5-HT3 antagonist ondansetron (Zofran). Postgrad Med J 1996:72:688-9.

44 Sullivan CA, Johnson CA, Roach $\mathrm{H}$, et al. A pilot study of intravenous ondansetron for hyperemesis gravidarum. Am J Obstet Gynecol 1996;174:1565-8
45 Wells CN. Treatment of hyperemesis gravidarum with cortisone. Am J Obstet Gynecol 1953;66:598-601.

46 Safari HR, Fassett M, Souter IC, et al. The efficacy of methylprednisolone in the treatment of hyperemesis gravidarum: a randomized, double-blind, controlled study. Am J Obstet Gynecol 1998;179:921-4.

47 Taylor R. Successful management of hyperemesis gravidarum using steroid therapy. Q J Med 1996;89:103-7.

48 Levine MG, Esser D. TPN for the treatment of severe hyperemesis gravidarum: maternal nutritional effects and fetal outcome. Obstet Gynecol 1988;72:102-7.

49 Boyce RA. Enteral nutrition in hyperemesis gravidarum: a new development. J Am Diet Assoc 1992;92:733.

50 Hsu JJ, Clark-Glena R, Nelson DK, et al. Nasogastric entereal feeding in the management of hyperemesis gravidarum. Obstet Gynecol 1996;88:343-6.

51 Tsang IS, Katz VL, Wells SD. Maternal and fetal outcomes in hyperemesis gravidarum. Int J Gynaecol Obstet 1996;55:231-5.

52 Hallak M, Tsalamandris K, Dombrowski MP, et al. Hyperemesis gravidarum. Effects on fetal outcome. J Reprod Med 1996;41:871-4.

\section{ANSWERS}

1. A; 2. E; 3. C; 4. E; 5. C. 